\title{
Editorials
}

\section{Hunger, overconsumption and youth: future directions for research in school-based public health nutrition strategies}

The search for strategies that can counteract the alarming growth in obesity among youth has fuelled considerable interest among public health nutrition researchers, policy makers and practitioners to examine ways in which school-based food and nutrition approaches can be effectively utilized to promote healthful eating. Historically, in most parts of the world, school food programmes were started to address inadequate nutrition, improve school attendance and enhance children's ability to learn. In this issue, Ashe and Sonnino(1) eloquently articulate that today, as we contend with the full spectrum of malnutrition - from hunger to overconsumption - in the same population, a fuller understanding of the potential benefit that strong school-based public health nutrition strategies could bring to society is warranted. Consequently there is a need to set future directions for research in school-based strategies that can have implications for policy and practice for improving the health and wellbeing of children across the world. In particular, there is a need to reflect on a new paradigm that is emerging around school foods - the idea that schools should be considered 'protected spaces' where young people enjoy and experience healthy food and nutrition environments.

This issue of Public Health Nutrition includes research articles on a broad range of topics related to health and school meal programmes. Based on this collective knowledge, below we identify themes and topics and propose a research agenda for school-based promotion of public health nutrition. Future research in this area should contribute new evidence to inform policy and develop strategies that take advantage of the opportunities that schools offer as a health-promoting setting.

\section{School meals and human rights}

The future direction for school meal programmes should take advantage of provisions in the broad framework of human rights of the child. The Convention on the Rights of the $\mathrm{Child}^{(2)}$ and the European Social Charter ${ }^{(3)}$ are examples of such provisions that stress the rights of the child to nutritious foods and to high standards of health. Since the obligation to recognize these rights falls on all societal actors, schools must take those rights into consideration when school food environments are designed. The range of contributions in this issue clearly shows that there is a growing consensus on the idea that schools should become 'protected spaces' in terms of what types of foods can be offered to and consumed by students during school hours. In addition, as pointed out in some of the papers $^{(1,4,5)}$, such protections should not be just passive restrictions based on availability, but should also include active learning about making healthy eating choices.

\section{One size doesn't fit all - local contexts are important}

Europe is a good example of how cultures related to diet and school foods can vary across regions and countries. Such differences are important considerations in setting new directions for research. The contributions from Patterson et $a l^{(6)}$, Sidaner et $a l^{(7)}$, Gelli and Espejo ${ }^{(8)}$, Bundy et $a l^{(9)}$ and Nelson ${ }^{(4)}$ in this issue clearly show the wide variety in national approaches to school meal provision in countries and regions such as Sweden, Brazil, Africa, the USA and England. This variation should be taken into account when the impact of school practices on eating patterns, health status and other outcome measures are assessed. The variation in national approaches to school meal programmes should also be taken into account when transnational policies and strategies are considered. For instance, this would be important in the ongoing attempts to integrate European school meal programmes in the next version of the European Common Agricultural Policy. In this instance, a valuable contribution from the research community could include an evaluation of different European approaches in terms of impact on commonly agreed upon outcome measures. In particular, it could be useful to compare these approaches with the approaches applied in other countries such as Brazil and the USA.

\section{A holistic approach is important}

Two papers in this issue suggest that education-only programmes or those based on experiential interventions (tasting, gardening, rewards) alone are not effective in improving children's consumption of healthful items ${ }^{(10,11)}$. Consequently a holistic and interdisciplinary approach is needed among all concerned stakeholders if school meal programmes are to make a significant difference in eating patterns of students. As pointed out by Wang and Stewart ${ }^{(12)}$, 
there is good evidence to support the effectiveness of the health-promoting schools approach and the whole-school approach for improving eating patterns among students. The whole-school approach underlines the importance of transdisciplinary cooperation and commitment from teachers, food service staff, school administration, parents and students in order to develop and maintain optimal school meal programmes. The whole-school approach also points to the fact that it is not only about making good and healthy food available but also about integrating food and nutrition in a broad range of subjects, projects and activities at school. Future research could focus on how school food environments can be turned into active learning spaces for both practitioners and young people by incorporating hands-on learning activities about food and nutrition into different school food venues. Such learning activities are an important part of the European Union-funded School Fruit Scheme ${ }^{(13)}$ and the US Department of Agriculture-funded Fresh Fruit and Vegetable Program ${ }^{(14)}$. The public health nutrition research community could further develop such approaches and investigate their impact and reach on consumption patterns among school children. In addition, efforts such as those by Townsend and Foster ${ }^{(15)}$ and Moore et al. ${ }^{(5)}$, who use the social ecological framework and explore the role of and interactions between factors and interventions at various levels, can also help identify complementary and costeffective multilevel strategies for improving children's consumption at school and beyond.

\section{Creating a consistent foodscape across schools}

Depending on the national and local policies, culture and contextual factors, availability of and participation in school meals can vary ${ }^{(7,16,17)}$. Over the last few years, policies and practices surrounding schools meals, especially those related to subsidized or free meal programmes, have received much attention in countries like the UK and the USA. As illustrated by Hirschman and Chriqui ${ }^{(17)}$ and Adamson et al. ${ }^{(18)}$ in this issue, guidance governing free and subsidized meals has become more stringent and consistent with the latest nutritional recommendations. Evidence suggests that improved school meal guidelines result in healthier meals served and consumed at schools. However, not all countries make school meals available, and not all students in countries that provide school meals partake in these programmes. As a result, students acquire food from multiple sources at school - food offered as part of school meals, food sold separately from school meals in different school venues such as vending machines and tuck shops, and packed lunches and snacks brought from home. Four papers in this issue address differences between meals brought from home $v$. meals served at school in the UK with somewhat conflicting results ${ }^{(19-22)}$. It is interesting to note that the studies that collected data after the introduction of new School Food Trust guidelines in the UK showed more favourable results for school lunches compared with packed lunches ${ }^{(20-22)}$, reinforcing the fact that school meals can be improved through changes in guidelines. Ray et $a l^{(16)}$ suggest that even in countries that do not offer school meals, school-level rules can be an effective strategy to improve children's consumption. In order to ensure that schools develop into 'protected spaces' the public health research community is faced with a challenge to identify feasible strategies that, in addition to supporting efforts to improve the nutritional quality of meals and snacks served by schools, also address ways to impact diets of children who either do not eat school meals or attend schools that do not provide them.

\section{Extending the healthy school environment beyond schools}

Availability of healthy options and lack of availability of unhealthy options in schools have consistently been shown to be associated with healthier consumption ${ }^{(23,24)}$. But in many instances, students face other less supportive environments outside schools. There is a need for more research on how healthy food environments in schools could be extended beyond the school premises and diffuse into local neighbourhoods. Partnership approaches and agreements with local food retailers could be an option and such approaches need to be explored and further researched. The important question is how to extend the benefits of school-based strategies to outof-school time, especially the after-school time.

\section{Monitoring and evaluation}

Monitoring and evaluation can and should guide policy development. Hirschman and Chriqui ${ }^{(17)}$ and Adamson et $a l^{(18)}$ provide excellent examples of how school food monitoring and evaluation research has been instrumental in influencing policies and guidelines related to school meals in the USA and the UK. Similar sustained efforts are needed in sub-Saharan African counties and other parts of the world to guide policy on school feeding programmes ${ }^{(8,9)}$. Improved international collaborations and research and practice networks could contribute in setting up evidencebased monitoring and evaluation methodologies.

\section{Engaging all stakeholders}

Increased exchange of ideas and evidence among practitioners, policy makers and researchers is needed in order to influence future policies. The contributions in this issue clearly show that school meal programmes can be approached from different perspectives and that countries use varied frameworks and approaches to develop school meal programmes. Countries like Brazil 
view school meals as a universal right of students enrolled in public basic education and consider it one of the most important strategies of national food security policy ${ }^{(7)}$. Others link school meals to local agriculture, children's rights and jobs creation, to help build political support for school meals ${ }^{(1)}$. In some cases, especially where no national school meal programme exists, best practices often develop from local action where committed champions help create healthy meal practices at schools. Examination and dissemination of such best practices requires a close cooperation and exchange of ideas among various stakeholders including practitioners and researchers. Given the diversity in approaches adopted across different countries, more international networking is needed both within the scientific community and also between practitioners and policy makers.

As the public health nutrition research in school settings moves forward, the schools as 'protected spaces' paradigm may be appropriate as a guiding principle to ensure that children in schools only have access to foods that positively influence their growth and development.

Bent Egberg Mikkelsen and Punam Ohri-Vachaspati Associate Editors

doi:10.1017/S1368980013001250

\section{Acknowledgement}

The authors would like to acknowledge Sarah Martinelli for her help in manuscript preparation.

\section{References}

1. Ashe L \& Sonnino R (2013) At the crossroads: new paradigms of food security, public health nutrition and school food. Public Health Nutr 16, 1020-1027.

2. United Nations, Office of the High Commissioner for Human Rights (1989) Convention on the Rights of the Child. http://www.ohchr.org/EN/ProfessionalInterest/Pages/ CRC.aspx (accessed April 2013).

3. Council of Europe, Treaty Office (1996) European Social Charter (revised), CETS No.: 163. http://conventions. coe.int/Treaty/Commun/QueVoulezVous.asp?NT $=163 \& \mathrm{CL}=$ ENG (accessed April 2013).

4. Nelson M (2013) School food cost-benefits: England. Public Health Nutr 16, 1006-1011.

5. Moore L, de Silva-Sanigorski A \& Moore SN (2013) A socioecological perspective on behavioural interventions to influence food choice in schools: alternative, complementary or synergistic? Public Health Nutr 16, 1000-1005.

6. Patterson E, Quetel A, Lilja K et al. (2013) Design, testing and validation of an innovative web-based instrument to evaluate school meal quality. Public Health Nutr 16, 1028-1036.
7. Sidaner E, Balaban D \& Burlandy L (2013) The Brazilian school feeding programme: an example of an integrated programme in support of food and nutrition security. Public Health Nutr 16, 989-994.

8. Gelli A \& Espejo F (2013) School feeding, moving from practice to policy: reflections on building sustainable monitoring and evaluation systems. Public Health Nutr 16, 995-999.

9. Bundy DA, Drake LJ \& Burbano C (2013) School food, politics and child health. Public Health Nutr 16, 1012-1019.

10. Upton D, Upton P \& Taylor C (2013) Increasing children's lunchtime consumption of fruit and vegetables: an evaluation of the Food Dudes programme. Public Health Nutr 16, 1066-1072.

11. Evans C, Ransley JK, Christian MS et al. (2013) A clusterrandomised controlled trial of a school-based fruit and vegetable intervention: Project Tomato. Public Health Nutr 16, 1073-1081.

12. Wang D \& Stewart D (2013) The implementation and effectiveness of school-based nutrition promotion programmes using a health-promoting schools approach: a systematic review. Public Health Nutr 16, 1082-1100.

13. European Commission, Agriculture and Rural Development (2011) About the EU School Fruit Scheme (SFS). http://ec.europa.eu/agriculture/fruit-and-vegetables/index_ en.htm (accessed April 2013).

14. US Department of Agriculture (2010) Fresh Fruit and Vegetable Program: A Handbook for Schools. http://www.fns.usda.gov/ cnd/FFVP/handbook.pdf (accessed April 2013).

15. Townsend N \& Foster C (2013) Developing and applying a socio-ecological model to the promotion of healthy eating in the school. Public Health Nutr 16, 1101-1108.

16. Ray C, Roos E, Brug J et al. (2013) Role of free school lunch in the associations between family-environmental factors and children's fruit and vegetable intake in four European countries. Public Health Nutr 16, 1109-1117.

17. Hirschman J \& Chriqui JF (2013) School food and nutrition policy, monitoring and evaluation in the USA. Public Health Nutr 16, 982-988.

18. Adamson A, Spence S, Reed L et al. (2013) School food standards in the UK: implementation and evaluation. Public Health Nutr 16, 968-981.

19. Prynne CJ, Handford C, Dunn V et al. (2013) The quality of midday meals eaten at school by adolescents; school lunches compared with packed lunches and their contribution to total energy and nutrient intakes. Public Health Nutr 16, 1118-1125.

20. Pearce J, Wood L \& Nelson M (2013) Lunchtime food and nutrient intakes of secondary-school pupils; a comparison of school lunches and packed lunches following the introduction of mandatory food-based standards for school lunch. Public Health Nutr 16, 1126-1131.

21. Harrison F, Jennings A, Jones A et al. (2013) Food and drink consumption at school lunchtime: the impact of lunch type and contribution to overall intake in British 9-10-year-old children. Public Health Nutr 16, 1132-1139.

22. Stevens L, Nicholas J, Wood L et al. (2013) School lunches $v$. packed lunches: a comparison of secondary schools in England following the introduction of compulsory school food standards. Public Health Nutr 16, 1037-1042.

23. Story M, Kaphingst KM \& French S (2006) The role of schools in obesity prevention. Future Child 16, 109-142.

24. Kubik MY, Lytle LA, Hannan PJ et al. (2003) The association of the school food environment with dietary behaviors of young adolescents. Am J Public Health 93, 1168-1173. 